\title{
Exploration or Exploitation? The Impact of Empowering Leadership on Ambidextrous Innovations for Medium-Sized Enterprises in China: The Moderating Role of Managerial Ties
}

\author{
Zhengyang $\mathrm{Wu}^{*} \quad$ Xiaobao Peng \\ School of Public Affairs, University of Science and Technology of China, Building of Management Academy, \\ No.96, Jinzhai Rd, Hefei, Anhui 230026, P.R.C
}

\begin{abstract}
The study focuses on the impact of empowering leadership on the ambidextrous innovation of SMEs in emerging economies. There are two types of definitions for ambidextrous innovation on the strategic perspective, balance and trade-off. In this article, we only discuss trade-off for the ambidextrous innovation of enterprises. On the one hand, we studied the influence mechanism of the empowering leadership behavior of SMEs on the ambidextrous innovation of SMEs in emerging economies, with the sample in China. On the other hand, the paper also reveals the role of managerial ties of leaders on the empowering leadership and ambidextrous innovation. Through the questionnaire survey and data analysis, we concluded that the leader's managerial ties could moderate the relationship between the empowering leadership and the SMEs' ambidextrous innovation willingness. The conclusions of this study provide a reference for the further development and reform of SMEs in China and other emerging economies.
\end{abstract}

Keywords: SME; Empowering leadership; Ambidextrous innovation; Managerial Ties

DOI: $10.7176 / \mathrm{EJBM} / 11-16-05$

Publication date: June $30^{\text {th }} 2019$

\section{Introduction}

With the gradual development of the economy in China, the role of SMEs in the national economy has become more and more prominent so that it has become a potential growth point for China's economy. In order to survive and sustain in a long time, enterprises need to improve their core competitiveness through innovation to provide new revenue growth points in the increasingly fierce market competition. Ambidextrous innovation is a balance between exploratory innovation and exploitative innovation. The combination of these two types of innovations can make the organization's survivability stronger and improve financial performance (Cottrell and Nault, 2004). Exploratory innovation is an innovative activity with experimental, risky and potentially high-yield benefits, while exploitative innovation focuses on performance improvements in the business and production processes (Smith and Tushman, 2005). However, compared with large enterprises, it is difficult for SMEs to achieve ambidextrous innovation due to the limited resources of SMEs. Therefore, different degrees of trade-offs must be made between exploratory innovation and exploitative innovation. In Chinese SMEs, paternalistic leadership is the main form of leadership (Wu et al., 2012). However, this leadership has the drawback of excessive centralization, which limits the creativity and enthusiasm of employees, and ultimately affects the ambidextrous innovation of SMEs. On the other hand, empowering leadership, as an emerging leadership style that can give full play to subordinate creativity, has received much attention in the organizational reform of enterprises in recent years. Then, it has become more and more favored by the theoretical circles and enterprise's leaders. Furthermore, research on empowering leadership can improve the competitiveness of SMEs in order to survive in the market competition during China's economic transition. Thus, it is of great value to study the influence of empowering leadership on the ambidextrous innovation willingness of SMEs.

According to the leadership theory, the existing literature has four main categories of organizational leadership behavior: 1. Directive leadership, is defined that the leader's power comes from his position. 2 . Transactional leadership, which relies on expectancy theory, equity theory, and reinforcement theory, gives a fair reward based on employee behavior so that employees expect to be met. 3. Transformational leadership, with leaders providing visions to the employees, aims to change the status quo (Pearce et al., 2003). 4. Empowering leadership, is defined that leaders encourage subordinates' autonomous behavior, opportunity thinking, teamwork, self-development, participation in goal development and self-reward (Pearce and Sims, 2002). At present, in the study of leadership as an antecedent variable of ambidextrous innovation, most of the research results show that leadership behavior has a clear impact on ambidextrous innovation. For example, Jansen has studied the influence of transformational leadership and transactional leadership on the ambidextrous innovation. And he pointed out two types of leadership behavior had different effects on ambidextrous innovation with the moderation of environmental dynamics (Jansen et al., 2009). Furthermore, Lin's research shows that strategic leadership behavior can promote the realization of ambidextrous innovation through the moderate role of knowledge sharing (Lin and McDonough, 2011). In summary, it can be seen that there is a gap for the research on the relationships between 
empowering leadership and the ambidextrous innovation of SMEs. Therefore, we aim to explore how empowering leadership influence SMEs' ambidextrous innovation.

On the other hand, the environment faced by SMEs is the Chinese market currently in the process of transformation. The weak market system, the lack of property rights protection and the uncertainty of the institutional environment are prominent features in China's transformation process (Nee, 1992). Therefore, the role of the market is weak. Moreover, the government has a large number of resources so that it is likely to intervene in normal market behavior (Nee, 1989). In the process of economic transformation, the business behavior of enterprises is restricted by high transaction costs and underdeveloped market systems. Then, enterprises have to seek the protection of informal institutions to protect their normal business practices (Boisot and Child, 1996, Keister, 2009). As we know, informal institutions play a substitute for the formal institutional role in the case of a lack of formal institutions (Xin and Pearce, 1996). For Chinese SMEs, managerial ties of leaders is a common and important informal system. The existing literature has conducted extensive research on the managerial ties of leaders in enterprises, and most of the literature studies the impact of social networks on personal accomplishments for leaders. The research from Peng and Luo shows that the managerial ties of leaders can be subdivided into business ties and political ties from a horizontal perspective (Peng and Luo, 2000). Moreover, existing research shows that managerial ties can improve a corporation's financial performance (Park and Luo, 2001). However, the existing research mostly focuses on the relationship between the social network and organizational performance, while the research on the impact of managerial ties to the ambidextrous innovation of SMEs is still relatively rare. Therefore, there is a high theoretical value for researchers to integrate managerial ties of SMEs with the empowering leadership and ambidextrous innovation into a whole framework.

The research in this paper will focus on the following two questions: 1 . How does the empowering leadership behavior of SMEs affect trade-offs activities for ambidextrous innovation? 2. How do the managerial ties of SMEs play a role in moderating these effects? With the two questions, this paper will conduct empirical research on small and medium-sized enterprises in China, planning to explore the relationship among empowering leadership, managerial ties, and ambidextrous innovation. Thus, our research will enrich the theory of leadership and ambidextrous innovation, and provide a theoretical reference for the development of SMEs.

\section{Hypothesis}

\subsection{Empowering leadership and exploratory innovation}

Empowering leadership stems from the concept of super leadership proposed by Manz and Sims (Manz C C, 1987). In addition, Pearce defines empowering leadership as an independent leadership behavior that is different from transformational leadership and transactional leadership (Pearce et al., 2003). At present, empowering leadership has two different dimensions of research perspective, while the research on innovation at the organizational level is mainly based on the perspective of context with empowerment ( $\mathrm{M}$ et al., 2005). From the perspective of context empowerment, empowering leadership behavior includes five aspects, taking the lead, participatory goal setting, information sharing, training and attention to subordinates(Arnold et al., 2000). For SMEs, empowering leadership behavior makes the leader himself a member of the organization, becoming a participant rather than a leader. Among the team, the leader's knowledge sharing will promote the team members to learn from each other. And even they will actively understand each team member's strengths and abilities so that the subordinates have a strong sense of trust to the leader (Srivastava et al., 2006). Moreover, leaders are more aware of the latest market trends and potential technological trends than other members are, so that other members of the team tend to choose exploratory innovations that will affect the long-term future of the enterprise. On the other hand, paying attention to subordinates is shown to encourage subordinates to challenge themselves and break through bottlenecks, so that employees will try some difficult research, such as the development of cutting-edge technologies and the prediction of future markets. Therefore, this kind of motivation of the leader to the employees can greatly stimulate the creativity and risk-taking of the subordinates (Zhang and Bartol, 2010), and then encourage the team members to have more possibilities to carry out exploratory innovation.

\section{Hypothesis 1: empowering leadership has a positive impact on the exploratory innovation of SMEs.}

\subsection{Empowering leadership and exploitative innovation}

In the environment of SMEs, the traditional leadership behavior conveyed to the subordinates' work intentions is often the ultimate pursuit of short-term profits. Therefore, it is easy for employees to fear the leaders, leading to the suppression of innovative ideas, and then employees dare not take the initiative to propose a new idea with the leader. This long-term relationship would undermine the subordinates' job satisfaction and perceived organizational support, thereby allowing subordinates afraid of making mistakes. Furthermore, the innovative behavior of the organization will become steady and cautious, so that enterprises are more likely to choose exploitative innovations. On the other hand, empowering leadership can change the negative situation, because empowering leadership can promote the participation goal setting for employees. Participatory goal setting means that the leader advocates the goal setting of the subordinate participating organizations, and encourages all 
members to discuss the planning of the organizational goals without the leaders intervening (Janz, 1999). Nevertheless, non-interference is not equal to letting things drift without controlling; leaders can develop the strategy through internal mutual supervision and support for self-targeting. Especially in knowledge-based SMEs, subordinates are often the important technical personnel, so the leaders would rely on the joint decision-making with subordinates while setting the goals. The potential goal of leaders in SMEs is often around the profitmaximizing innovation activities, so the subordinates will take into account the long-term development of the enterprise rather than the short-term profit because of the purpose of being able to stay in the enterprise for a long time with the higher salary. Since the goal of organizational innovation depends on the common pursuit of team members rather than the idea of one leader (P. and C., 1997), the leader's decision that plan to earn more shortterm profits will not be available in the participatory goal setting. Then, team members will consider longer-term benefits in the process of setting up innovation goals, which will lead to a greater tendency for the final organization to opt out of exploitative innovation.

Hypothesis 2: Empowering leadership has a negative impact on the exploitative innovation of SMEs.

\subsection{The moderation of business ties}

Managerial ties can be divided into political ties and business ties. For SMEs, due to the limited resources of themselves, they must rely on a large number of business partners to survive in a fiercely competitive market. These business partners include suppliers, partners, and even competitors (Peng and Luo, 2000). Individual SMEs cannot grasp all the market trends, product trends, and technological developments, but multiple business partners of SMEs may have similar information on a considerable scale (Yang et al., 2014). If SME leaders maintain good personal friendships with these business partners, they can understand the changes in the market and the development of cutting-edge technologies in time. Therefore, SMEs can get the demand for new products and potential technology from costumers as soon as possible. Since this information is known in advance, the leader will inevitably encourage the subordinates to try the exploratory innovation with a certain risk for seizing the future competitive advantage. At the same time, the enterprises can more easily find partners for the research of new products and new technologies with the good business ties of the leaders ( $\mathrm{Su}$ and Yang, 2018), which indirectly reduces the risk of exploratory innovation. Therefore, these good business ties enhance the positive impact of empowering leadership on the willingness of exploratory innovation of SMEs.

Hypothesis 3a: Leaders' business ties can strengthen the positive impact of empowering leadership on exploratory innovation of SMEs.

On the other hand, the relationship between SME leaders and business partners will also influence the participation goal setting among empowering leadership. Since the subordinates mainly complete the participation goal setting, they tend to consider the long-term development of the SMEs for staying in the enterprise in a long time. Therefore, the employees tend to exclude exploitative innovation, which focus on short-term benefits maximization. When the leader's business ties are stronger, SMEs can get products or raw materials from suppliers at lower prices, and get better discounts from sellers (Su et al., 2015). Thus, good business ties can bring a lot of benefits to SMEs in the short term. Meanwhile, under the influence of the empowering leadership, the subordinates will take into account the fact that the exploitative innovation requires fewer resources but can obtain more shortterm benefits, and the risk is lower than before. Due to the existence of participatory goal settings, the employees mainly determine organizational decision-making rather than leaders. Therefore, empowering leadership will make it more likely that subordinates will invest existing resources into exploitative innovation. Therefore, if the leader has good business ties, the negative impact of the empowering leadership on the organization's exploitative innovation will be weakened.

Hypothesis 3b: Leaders' business ties can weaken the negative impact of empowering leadership on exploitative innovation of SMEs.

\subsection{The moderation of political ties}

From the perspective of the resources of SMEs, the influence of leaders' business ties and political ties is different. The business ties of the leader are generally long-term ( $\mathrm{Li}$ et al., 2008), because the relationship between the business partners is mainly conducted by the cooperation between the two parties to achieve a win-win result in market share and sales performance. Thus, the cooperation of business partners does not aim at directly benefiting from the other enterprise. However, the political ties are not as same as business ties. The establishment, maintenance, and enhancement of the leader's political ties are aimed at the short-term financial benefits of the other party (Danneels, 2002). The good political ties of SME leaders often means that the enterprise cannot use all the resources for the innovation activities, because they must divert some resources to maintain the good political ties that leaders have established(Sheng et al., 2011). Therefore, good political ties of SMEs will inevitably sacrifice some of their own resources. Moreover, the organization's resources are important for SMEs, especially financial resources, which are invaluable and scarce. Meanwhile, exploratory innovation is a high-risk innovation that consumes a lot of resources of SMEs. Once leaders need to develop good political ties, which will squeeze 
out the scarce resources of enterprises, there are not enough resources for enterprises to develop new products and technologies. Finally, under the influence of empowering leadership, it is more difficult for subordinates to choose exploratory innovation as the enterprise's strategy.

Hypothesis 4a: The political ties can weaken the positive impact of empowering leadership on the exploratory innovation of SMEs.

In the context of the economic transition period currently faced by SMEs, the government has a large number of resources, but the decision-making mechanism cannot be completely fair and open. Therefore, business leaders can rely on good personal friendships with government officials to gain a certain competitive advantage in terms of new products, market access for new businesses, and government procurement tenders (Su et al., 2015). For SMEs, the time for approval of new products and technologies is very important. The lower the time cost in this process can bring greater profits and market competitiveness. In addition, the leaders who have good political ties can easily obtain the winning bids for government procurement. Then, such opportunities can also enhance larger financial resources to SMEs in the short term. Therefore, good political ties of leaders can effectively reduce the economic and time costs of SMEs' innovation activities (Su and Yang, 2018), and create a favorable opportunity for enterprises to obtain large profits in a short period. Meanwhile, under the information sharing mechanism of empowering leadership behavior, subordinates are more likely to tend to grasp the opportunities of good political ties brought by leaders when setting goals. Above all, the SME will have a greater willingness to choose exploitative innovation so that companies can get a number of benefits in the short term.

Hypothesis $4 \mathrm{~b}$ : The political ties can weaken the negative impact of empowering leadership on exploitative innovation of SMEs.

\section{Methods}

3.1 Data and samples

The Yangtze River Delta region is one of the most active and dynamic regions of China's SMEs. It is also the most developed economic belt and urban agglomeration in China. The competition between SMEs is the most intense, and business cooperation is also the closest. Thus, we have finally chosen Jiangsu, Zhejiang, and Shanghai as the main research sites, and joined a small number of samples from Beijing and Wuhan to conduct research on local SMEs. We used interviews, e-mail, and online survey tools as research methods for SMEs in such regions and cities among the senior management team. To be more specific, we used a snowball sampling method to distribute the questionnaire to each top leader and its direct subordinates (i.e. TMT members) in order to ensure that the respondents are leaders with decision-making power in SMEs. First, we contacted 672 leaders of SMEs, from Beijing, Wuhan and several cities in East China and sent the questionnaires to them. Second, we received 313 questionnaires in one month and then we summarized all the questionnaires. Finally, after eliminating the obvious invalid questionnaire, we obtained 228 valid questionnaires. Among the data, the correlation test of the quarterpoint questionnaires in the early and late stages is carried out. The results show that there is no significant difference between several variables at the 0.05 significance level, indicating that the samples are representative.

\subsection{Variable measurement}

The questionnaire consisted of five variables totaling 37 items, divided into three parts: independent variable, moderate variable, and dependent variable. All the items in this questionnaire are consisted of the Likert 7-point scale, 1 means completely disagree, 7 means complete agreement, and the middle gradually changes according to the degree of consent.

The section of the independent variable includes measurements of empowering leadership, for 22 items. The most famous scale used for empowering leadership measurement is the Empowering Leadership Theory Framework Scale from Arnold, which includes 38 items in five dimensions (Arnold et al., 2000). Since there are quite a few items that are not applicable to the measurement of empowering leadership behavior of SMEs in the Chinese mainland context, we have used the scale developed by Pearce and Sims in the measurement of empowering leadership. The scale content is divided into six dimensions(Pearce and Sims, 2002), including encouraging self-reward ( 3 items), encouraging teamwork ( 3 items), and participating in goal setting ( 3 items), encourage autonomous behavior ( 4 items), encourage opportunity thinking (3 items) and encourage selfdevelopment (6 items). Since the respondents to the questionnaire are leaders rather than employees, we have revised some of the topics related to the perception and evaluation of subordinates. Furthermore, the method of back-translation is used in the process of translation to distinguish the differences between items of the same dimension as much as possible. Finally, the measurement of each dimension of empowering leadership appears like the average of multiple items.

The part of the moderate variables is mainly the managerial ties, including the two variables of political ties and business ties. The measurement of the managerial ties is used by the study of Peng and Luo. The study shows that we can use the three dimensions of the leader's personal friendship with customers, suppliers, and competitors to represent the business ties of SMEs. Meanwhile, we can also use the four dimensions of the personal friendship 
between the leader and the local government department, business administration department, tax department and state-owned bank to represent the political ties of SMEs (Peng and Luo, 2000). The two scales contain a total of seven items.

The dependent variable component includes two variables, exploratory innovation and exploitative innovation. The measurement of the trade-off for the ambidextrous innovation of SMEs draws on the research from He and Wong. There are four items of exploratory innovation in the scale, including the pursuit of new technologies by enterprises, the courage of enterprises to undertake R\&D risks, the types of products extended by enterprises, and the attitude of the enterprise to open up new markets. The scale for exploitative innovation also includes four items, the attitude of enterprises to improve existing products, the enthusiasm of enterprises to provide services to customers, the pursuit of enterprises to reduce production costs, and the willingness to consolidate existing markets (He and Wong, 2004). Above all, there are eight items in this section.

\subsection{Control variables}

The time of enterprises established will affect the technological innovation inputs and outputs, resulting in differences in the resources of SMEs. Moreover, the established time must have an impact on the ambidextrous innovation of SMEs. Hence, the established time should be added to the model as control variables. Due to differences in career and departmental contexts, leaders will compete for the choice of exploratory and exploitative innovations through Self-Reinforcing (March, 1991). Therefore, the number of SME leaders must also be included in the control variables. In addition, the personal background of the leader will also affect the organization's ambidextrous innovation. Okamuro's research shows that the educational background of leaders directly affects corporate innovation behavior (Okamuro and Honjo, 2011), including education levels and graduate schools. On the other hand, the leader's age, gender, years of work, and departmental work time can cause differences in management experience, and then recognize the characteristics of two different innovation activities to make different decisions (Birkinshaw et al., 2008). Therefore, the leader's personal background includes the following six control variables: the gender of the leader, the age, the working years, the department's working time, the graduate school and the education level, which are also treated as control variables. In summary, we plan to introduce the following eight control variables: company establishment time, leader gender, age, working years, department work time, education level, graduate school, and the number of leaders.

\section{Data Analyses}

\subsection{Reliability and validity test}

We tested the reliability and validity of each variable by SPSS22.0. As can be seen from Table-1, the Cronbach's $\alpha$ coefficient for empowering leadership is 0.763 . The Cronbach's $\alpha$ coefficients for leaders' political ties and business ties are 0.827 and 0.758 . The Cronbach's $\alpha$ coefficients for SMEs' exploratory innovation and exploitative innovation are 0.891 and 0.706 . As shown in the table, we can see the Cronbach's $\alpha$ coefficients of these five variables are all higher than 0.7 , indicating that the questionnaire has good reliability.

On the other hand, our analysis of the KMO values of the five variables is shown in Table- 1 . As can be seen from the chart, the KMO value of empowering leadership behavior is 0.728 . The KMO values for leaders' political ties and business ties are 0.751 and 0.709 . The KMO values of SMEs' exploratory innovation and exploitative innovation are 0.818 and 0.717 . It can be found that the KMO values of each variable are greater than 0.7 , indicating that exploratory factor analysis can be performed.

Table 1. Reliability Test

\begin{tabular}{|l|l|l|}
\hline & Cronbach's $\alpha$ coefficients & KMO \\
\hline Empowering Leadership & 0.763 & 0.728 \\
\hline Political Ties & 0.827 & 0.751 \\
\hline Business Ties & 0.758 & 0.709 \\
\hline Exploratory Innovation & 0.891 & 0.818 \\
\hline Exploitative Innovation & 0.706 & 0.717 \\
\hline
\end{tabular}

\subsection{Exploratory factor analysis}

By exploratory factor analysis (EFA) on the questionnaire scale, we can see that the factor load of most items is above 0.7 in Table-2. However, the factor loads of "encourage self-reward", "encourage teamwork" and "participation goal setting" in empowering leadership are 0.698, 0.679 and 0.654 , which are lower than the factor load factors of other items. Even so, the factor-loading coefficient of all items is greater than 0.65 , indicating that the questionnaire has good structural validity. 
Table 2. EFA results

\begin{tabular}{|l|l|}
\hline & The Factor Loads \\
\hline Empowering Leadership & \\
\hline Encouraging self-reward & 0.698 \\
\hline Encouraging teamwork & 0.679 \\
\hline Participating in goal setting & 0.654 \\
\hline Encouraging autonomous behavior & 0.892 \\
\hline Encouraging opportunity thinking & 0.789 \\
\hline Encouraging self-development & 0.877 \\
\hline Business Ties & \\
\hline Friendship with customers & 0.868 \\
\hline Friendship with suppliers & 0.793 \\
\hline Friendship with competitors & 0.783 \\
\hline Political Ties & \\
\hline Friendship with local government & 0.792 \\
\hline Friendship with business administration department & 0.824 \\
\hline Friendship with tax department & 0.831 \\
\hline Friendship with state-own bank & 0.775 \\
\hline Exploratory Innovation & \\
\hline Pursuit of new technologies & 0.855 \\
\hline Courage to undertake R\&D risks & 0.815 \\
\hline Types of products extended & 0.765 \\
\hline Attitude to open up new markets & 0.796 \\
\hline Exploitative Innovation & \\
\hline Attitude to improve existing products & 0.718 \\
\hline Enthusiasm to provide services to customers & 0.724 \\
\hline Pursuit to reduce production costs & 0.701 \\
\hline The willingness to consolidate existing markets & 0.745 \\
\hline & \\
\hline
\end{tabular}

\subsection{Descriptive statistics}

The mean and standard deviation of each variable are shown in Table-3. We can find that all the main variables except the control variables have a mean value higher than 4.00, indicating that each variable has a higher utilization rate. In the bivariate correlation analysis, we can see that the empowering leadership behavior of SMEs and exploratory innovation have a significant positive correlation $(\mathrm{r}=0.828, \mathrm{p} \leq 0.01)$, which is consistent with the main effect in the model. In the control variables section, we can find that there is a significant negative correlation between leaders' age and exploratory innovation $(\mathrm{r}=0.139, \mathrm{p} \leq 0.05)$, while the leadership department's working time and exploratory innovation show a significant positive correlation $(\mathrm{r}=0.215, \mathrm{p} \leq 0.01)$. This phenomenon also preliminarily verified the need to incorporate the leader's personal attributes into the control variables.

Table 3. Descriptive statistics

\begin{tabular}{|c|c|c|c|c|c|c|c|c|c|c|c|c|c|c|c|c|}
\hline & & Mean & S.D & 1 & 2 & 3 & 4 & 5 & 6 & 7 & 8 & 9 & 10 & 11 & 12 & 13 \\
\hline 1 & Establishment time & 3.930 & 2.714 & 1.000 & & & & & & & & & & & & \\
\hline 2 & Gender & 1.170 & 0.377 & -0.06 & 1.000 & & & & & & & & & & & \\
\hline 3 & Age & 33.509 & 2.429 & -0.541 & $0.217^{* *}$ & 1.000 & & & & & & & & & & \\
\hline 4 & Education level & 2.501 & 0.873 & -0.123 & 0.049 & 0.014 & 1.000 & & & & & & & & & \\
\hline 5 & Graduate school & 1.930 & 0.629 & 0.591 & 0.017 & 0.007 & -0.045 & 1.000 & & & & & & & & \\
\hline 6 & Working years & 2.612 & 1.228 & 0.587 & -0.045 & -0.063 & -0.074 & $-0.198^{* *}$ & 1.000 & & & & & & & \\
\hline 7 & Department work time & 1.354 & 0.601 & -0.37 & 0.026 & 0.004 & -0.005 & -0.035 & 0.109 & 1.000 & & & & & & \\
\hline 8 & Number of leaders & 6.452 & 2.265 & -0.231 & -0.029 & 0.003 & 0.015 & -0.085 & 0.003 & -0.013 & 1.000 & & & & & \\
\hline 9 & Empowering Leadership & 4.088 & 1.278 & -0.401 & -0.104 & $-0.146^{*}$ & $-0.134 *$ & 0.041 & 0.012 & $0.215^{* *}$ & 0.026 & 1.000 & & & & \\
\hline 10 & Political Ties & 5.078 & 1.079 & 0.209 & -0.073 & 0.072 & 0.128 & -0.064 & 0.092 & -0.01 & 0.026 & -0.024 & 1.000 & & & \\
\hline 11 & Business Ties & 4.756 & 1.175 & $0.223^{* *}$ & 0.052 & 0.073 & -0.022 & -0.029 & -0.023 & -0.109 & -0.031 & -0.027 & 0.063 & 1.000 & & \\
\hline 12 & Exploratory Innovation & 4.432 & 1.372 & -0.102 & $-0.158^{*}$ & $-0.139 *$ & -0.075 & 0.015 & 0.01 & $0.211^{* *}$ & 0.097 & $0.828 * *$ & $0.272^{* *}$ & -0.024 & 1.000 & \\
\hline 13 & Exploitative Innovation & 5.387 & 0.702 & -0.256 & 0.048 & 0.006 & -0.072 & -0.057 & 0.015 & 0.102 & 0.027 & 0.087 & 0.088 & 0.124 & $0.163^{*}$ & 1.000 \\
\hline
\end{tabular}




\subsection{Hypothesis testing}

We used SPSS22.0 software for data analysis and Cohen's hierarchical regression method for hypothesis testing (Jacob Cohen, 1983). Specifically, we divide exploratory innovation and exploitative innovation into two groups. The exploratory innovation of the regression equation is in Model 1-4, and the exploitative innovation of the regression equation is in Model 5-8. We first put eight control variables in Model 1. Second, we put the empowering leadership as an independent variable into Model 2. Then, we put two moderate variables in Model 3 - the leader's political ties and business ties. Finally, we put the interactions between empowering leadership and exploratory innovation in Model 4. Moreover, Model 5-8 operates in a similar manner to Model1-4. The results of multiple linear regression are shown in Table-4.

Table 4. Hypothesis Testing

\begin{tabular}{|c|c|c|c|c|c|c|c|c|}
\hline & \multicolumn{4}{|c|}{ Exploratory Innovation } & \multicolumn{4}{|c|}{ Exploitative Innovation } \\
\hline & M1 & M2 & M3 & M4 & M5 & M6 & M7 & M8 \\
\hline \multicolumn{9}{|l|}{ Control Variable } \\
\hline Establishment time & -0.276 & -0.021 & -0.239 & 0.144 & 0.049 & -0.039 & -1.57 & -1.416 \\
\hline Gender & -1.212 & -0.816 & 0.074 & 0.149 & 1.108 & 0.956 & 0.771 & 0.599 \\
\hline Age & -0.479 & 0.357 & 0.543 & -0.824 & 0.601 & 0.325 & -0.173 & -0.047 \\
\hline Education level & -1.044 & -0.266 & -1.027 & -1.055 & -1.597 & $-1.865^{*}$ & $-1.870^{*}$ & $-1.792 *$ \\
\hline Graduate school & 0.078 & -0.21 & -0.103 & 0.395 & -0.301 & -0.21 & 0.152 & 0.345 \\
\hline Working years & 0.859 & 1.084 & 0.508 & 0.308 & -1.024 & -1.077 & -0.972 & -0.752 \\
\hline Department work time & 1.595 & 0.243 & 0.766 & 1.126 & -0.338 & 0.123 & 0.838 & 0.977 \\
\hline Number of leaders & 0.966 & 0.835 & 0.649 & 0.982 & -0.358 & -0.292 & -0.106 & -0.11 \\
\hline \multicolumn{9}{|l|}{ Independent Variable } \\
\hline Empowering Leadership & & $6.501 * *$ & $6.347 * *$ & $6.617 * *$ & & $-2.037 *$ & $-2.356^{*}$ & $-2.440 * *$ \\
\hline \multicolumn{9}{|l|}{ Moderate Variable } \\
\hline Political Ties & & & $7.382 *$ & $7.454 *$ & & & 0.069 & -0.194 \\
\hline Business Ties & & & 0.061 & 0.478 & & & $6.646^{*}$ & $6.342 *$ \\
\hline \multicolumn{9}{|l|}{ Interaction } \\
\hline PT*EL & & & & $-3.098 * *$ & & & & 1.323 \\
\hline $\mathrm{BT} * \mathrm{EL}$ & & & & $2.03 *$ & & & & $3.082 * *$ \\
\hline $\mathrm{R} 2$ & 0.036 & 0.192 & 0.355 & 0.397 & 0.025 & 0.043 & 0.206 & 0.244 \\
\hline$\triangle \mathrm{R} 2$ & 0.036 & 0.156 & 0.163 & 0.041 & 0.025 & 0.018 & 0.163 & 0.038 \\
\hline $\mathrm{F}$ & 1.019 & $5.770 * *$ & $10.825^{* *}$ & $10.83 * *$ & 0.704 & $1.096^{*}$ & $5.095 * *$ & $5.309 * *$ \\
\hline$\triangle \mathrm{F}$ & 1.019 & $42.244 * *$ & $27.304 * *$ & $7.354 * *$ & 0.704 & $4.149 *$ & $22.134 * *$ & $5.357 * *$ \\
\hline
\end{tabular}

In Model 1, eight control variables have no significant impact on SMEs' exploratory innovation. Model 2 responds to the main effect. It can be seen that the empowering leadership behavior of SMEs $(\beta=6.5, p \leq 0.01$, $\mathrm{F}=5.77$ ) has a significant positive impact on exploratory innovation. Therefore, Hypothesis 1 is validated, indicating that empowering leadership leads enterprises to choose exploratory innovation while the enterprise has to face with the trade-off. Model 3 and Model 4 show the effects of moderate effects. As can be seen from Table4, when leaders have better political ties, the impact of empowering leadership on exploratory innovation has changed from a significant positive impact in Model 2 to a significant negative impact in Model 4. That is to say, the leader's political ties weaken the positive impact of empowering leadership $(\beta=-3.098, p \leq 0.01, F=10.83)$ on the exploratory innovation of SMEs, and Hypothesis $4 \mathrm{a}$ is also verified. On the other hand, it can be seen from the table that the business ties of SME leaders will enhance the positive impact of empowering leadership $(\beta=2.03$, $\mathrm{p} \leq 0.05, \mathrm{~F}=10.83$ ) on the exploratory innovation of enterprises, so Hypothesis $3 \mathrm{a}$ is verified. This shows that under the condition that the leader's business ties are good, the empowering leadership behavior will lead the SMEs to prefer the exploratory innovation.

In Model 5, we found that only the education level of the leaders among the eight control variables had a significant negative impact on SME exploitative innovation. In the main effect verification of Model 6 , it can be seen that the empowering leadership behavior of SMEs $(\beta=-2.037, \mathrm{p} \leq 0.05, \mathrm{~F}=1.096)$ has a significant negative impact on the exploitative innovation. Therefore, Hypothesis 2 is validated, which indicates that empowering leadership behavior will enable SMEs to exclude exploitative innovation and choose exploratory innovation. Regarding the interaction term part, Model 7 and Model 8 reflect the effects of moderation. As shown in Table- 4 , when SME leaders have good business ties, the impact of empowering leadership on exploitative innovation has changed from a significant negative impact of Model 6 to a significant positive impact $(\beta=3.082, p \leq 0.01, F=5.309)$ in Model 8. That is to say, when the leader's business ties are better, the enterprise no longer rejects the exploitative innovation, but prefers to exploitative innovation. Therefore, Hypothesis $3 \mathrm{~b}$ is verified here. On the other hand, Model 8 shows that the interaction term is not significant $(\beta=1.323, p>0.10, F=5.309)$ when the leader's political ties are played as a moderator. Therefore, it does not mean that the leader's political ties can weaken the negative impact of the empowering leadership on the exploitative innovation in SMEs. Therefore, hypothesis $4 \mathrm{~b}$ is not 
supported by the data.

\section{Discussion and research conclusions}

For most SME leaders, empowering leadership is a new type of leadership, as a direction for China's leadership reform. Because of many reasons, the ambidextrous innovation of SMEs cannot keep balance like that of large companies. Therefore, the leaders of SMEs are very eager to understand what impact of the empowering leadership will play on the trade-off activities for the ambidextrous innovation of SMEs. Therefore, the problem solved in this study is how the empowering leadership and managerial ties of SME leaders will affect the trade-off strategy for SMEs' ambidextrous innovation.

Through theoretical assumptions and empirical analysis, we draw the following three conclusions. First, empowering leadership can positively influence the exploratory innovation of SMEs, but it can negatively influence the exploitative innovation. This means that empowering leadership can lead SMEs to choose exploratory innovation and exclude exploitative innovation without considering other factors. Secondly, in the context of good political ties, the impact of empowering leadership on the exploratory innovation of SMEs will change from positive to negative, while the impact of empowering leadership on exploitative innovation will change from negative to positive. Although the results of the hypothesis tests show that the moderate effect of political ties on empowering leadership and exploitative innovation is not significant, we believe that the reason for this result is the error in the data. Therefore, it can be admitted that the empowering leadership will make the organizations change from choosing exploratory innovation to choosing exploitative innovation if the leader has good political ties. On the other hand, we can find the result in the context of good business ties that, the positive impact of empowering leadership on exploratory innovation can be exactly strengthened, and the impact of empowering leadership on exploitative innovation will change from negative to positive. This means that if the leader has good business ties, the empowering leadership behavior will positively affect both exploratory innovation and exploitative innovation for SMEs. However, in this case, we cannot judge which strategy the SMEs will choose between exploratory innovation and exploitative innovation.

The main theoretical contribution of this research is to explore the influence of the empowering leadership on ambidextrous innovation and its applicable conditions from the perspective of the social networks of SME leaders. Due to the current stereotypes of most Chinese business leaders and the limitations of cultural traditions, the empowering leadership from developed countries can be unfamiliar to Chinese business leaders in SMEs. Therefore, there are relatively few research and applications involving empowering leadership. Furthermore, our research object is the empowering leadership behavior of Chinese SMEs. In this study, we have clarified the impact of empowering leadership on ambidextrous innovations and improved the research on the leadership theory of Chinese localized enterprises. On the other hand, due to many reasons such as national conditions and environment, the role of SME leaders in political ties and business ties in the trade-off for ambidextrous innovation is also different from that of developed countries. The sample data shows that the average political ties of SME leaders (5.08) are significantly higher than the average of business ties (4.76), which occurs when the sample data is mostly from the Yangtze River Delta. As is known to all, China's Yangtze River Delta region has developed private economies and less government intervention. This shows that the leader's political ties are of great importance to Chinese SMEs. We studied the managerial ties of China's SMEs and their moderate effects. We point out that the empowering leadership has a diametrically opposite effect on the ambidextrous innovation of SMEs, under the conditions of different managerial ties in SMEs. This discovery enriches the connotation of the innovation management theory of Chinese enterprises.

For the leaders of SMEs in China, the value of this research is to provide reference guidance for SMEs to carry out trade-off activities for ambidextrous innovation in the context of leadership behavior reform in China. The fact in SMEs shows that traditional paternalistic leadership has been unable to bring more efficiency to SMEs in today's economic transition in China. Therefore, once the leadership behavior pattern of SMEs is reformed toward the direction of empowering leadership, the ambidextrous innovation will inevitably change. When SMEs are dominated by empowering leadership styles, once the leader's political ties become better, the leaders should lead the enterprise to carry out exploitative innovation. On the other hand, when the business ties of SMEs are better, the benefits of exploratory innovation and exploitative innovation are both great, and the leaders of SMEs need to make further decisions to carry out the suitable innovation activities between the two innovation strategies. Meanwhile, leaders should try to improve their business ties, because good business ties are very helpful to both the innovation activities of the company.

\section{Limitations and future directions}

As mentioned above, although this study has some innovations in theory and practice, there are still three shortcomings in this study. First, due to limited conditions, the source of empirical data in this paper is relatively simple. The vast majority of samples were from several cities in the Yangtze River Delta region, and a small sample was selected from Beijing and Wuhan. We all know that there are many small and medium-sized 
enterprises in the Yangtze River Delta, and private capital is developed. Moreover, Beijing and Wuhan are also representatives of large cities in China, and they have the above characteristics, too. Therefore, the sample of this study represents SMEs in China's economically developed regions, and may not fully represent the situation of SMEs in mainland China. Secondly, in order to facilitate sampling, the sample of SMEs in this study is all selected from high-tech enterprises, and no other SMEs in the traditional industry sector participate, resulting in a relatively simple industry structure of sample companies. Furthermore, SMEs in different industries will have certain differences in the understanding of empowering leadership, so that the differences will also influence the selection tendency of a trade-off for ambidextrous innovation. Finally, the key point of this study is whether managerial ties have moderates effects. We only verified whether the managerial ties would lead to a change in the direction between the empowering leadership and SMEs' trade-off for ambidextrous innovation, but we did not study the lateral comparison of the intensity of influence of managerial ties. When the leader's business ties are good, the empowering leadership will simultaneously act on the exploratory innovation and exploitative innovation positively. In this case, there is no way to clearly determine which innovation strategy the leader should choose between exploratory innovation exploitative innovation, so further research is needed.

In view of the limitations of the above studies, future research can focus on the following three aspects. First, it is necessary that the sampling range should be expanded in the study. For example, it can be sampled in different provinces across the country, so that the results of empirical data are more representative. Secondly, this study focuses on the trade-off of SMEs' ambidextrous innovation, but the balance of SMEs' ambidextrous innovation is also worth studying. We believed that a variety of different leadership behaviors would have a different impact on the balance of SMEs' ambidextrous innovation. Finally, in addition to the political ties and business ties, the moderate effect of other variables to ambidextrous innovation is also worth investigating. In summary, these issues are waiting for future generations to study.

\section{References}

Arnold, J. A., Arad, S., Rhoades, J. A. \& Drasgow, F. (2000), "The empowering leadership questionnaire: the construction and validation of a new scale for measuring leader behaviors", Journal of Organizational Behavior, Vol. 21 No. 3, pp. 249-269.

Birkinshaw, J., Hamel, G. \& Mol, M. J. (2008), "Management Innovation", Academy of Management Review, Vol. 33 No. 4, pp. 825-845.

Boisot, M. \& Child, J. (1996), "From Fiefs to Clans and Network Capitalism: Explaining China's Emerging Economic Order", Administrative Science Quarterly, No. No.4, pp. 600-628.

Cottrell, T. \& Nault, B. R. (2004), "Product variety and firm survival in the microcomputer software industry", Strategic Management Journal, Vol. 25 No. 10, pp. 1005-1025.

Danneels, E. (2002), "The dynamics of product innovation and firm competences", Strategic Management Journal, Vol. 23 No. 12, pp. 1095-1121.

He, Z. L. \& Wong, P. K. (2004), "Exploration vs. exploitation: An empirical test of the ambidexterity hypothesis", Organization Science, Vol. 15 No. 4, pp. 481-494.

Jacob Cohen, P. C. (1983), Applied multiple regression correlation analysis for the behavioral sciences, L. Erlbaum Associates.

Jansen, J. J. P., Vera, D. \& Crossan, M. (2009), "Strategic leadership for exploration and exploitation: The moderating role of environmental dynamism", The Leadership Quarterly, Vol. 20 No. 1, pp. 5-18.

Janz, B. D. (1999), "Self-directed teams in IS: correlates for improved systems development work outcomes", Information \& Management, Vol. 35 No. 3, pp. 171-192.

Keister, L. A. (2009), "Organizational research on market transition: A sociological approach", Asia Pacific Journal of Management, No. No.4, pp. 719-742.

Li, J. J., Poppo, L. \& Zhou, K. Z. (2008), "Do managerial ties in China always produce value? Competition, uncertainty, and domestic vs. foreign firms", Strategic Management Journal, Vol. 29 No. 4, pp. 383-400.

Lin, H. \& Mcdonough, E. F. I. (2011), "Investigating the Role of Leadership and Organizational Culture in Fostering Innovation Ambidexterity", IEEE Transactions on Engineering Management, Vol. 58 No. 3, pp. 497-509.

M, A., J, M. \& A., R. (2005), "To empower or not to empower your sales force? An empirical examination of the influence of leadership empowerment behavior on customer satisfaction and performance", Journal of Applied Psychology, No. No.5, pp. 945-955.

Manz C C, S. H. (1987), "Leading Workers to Lead Themselves: The External Leadership of Self- Managing Work Teams", Administrative Science Quarterly, No. No.1, pp. 106-129.

March, J. G. (1991), "Exploration and Exploitation in Organizational Learning", Organization Science, Vol. 2 No. 1, pp. 71-87.

Nee, V. (1989), "A Theory of Market Transition: From Redistribution to Markets in State Socialism", American Sociological Review, No. No.5, pp. 663-681. 
Nee, V. (1992), "Organizational Dynamics of Market Transition: Hybrid Forms, Property Rights, and Mixed Economy in China", Administrative Science Quarterly, No. No.1, pp. 1-27.

Okamuro, H. \& Honjo, M. K. A. Y. (2011), "Determinants of R\&D cooperation in Japanese start-ups", Research Policy, No. No.5, pp. 728-738.

P., S. H. \& C., M. C. (1997), "Company of Heroes: Unleashing the Power of Self-leadership", Long Range Planning, No. No.1, pp. 141.

Park, S. H. \& Luo, Y. (2001), "Guanxi and organizational dynamics: organizational networking in Chinese firms", Strategic Management Journal, No. No.5, pp. 455-477.

Pearce, C. L. \& Sims, H. P. (2002), "Vertical versus shared leadership as predictors of the effectiveness of change management teams: An examination of aversive, directive, transactional, transformational, and empowering leader behaviors", Group Dynamics-Theory Research and Practice, Vol. 6 No. 2, pp. 172-197.

Pearce, C. L., JR, H. P. S., Cox, J. F., Ball, G., Schnell, E., Smith, K. A. \& Trevino, L. (2003), "Transactors, transformers and beyond: A multi-method development of a theoretical typology of leadership", The Journal of Management Development, No. NO.4, pp. 273-307.

Peng, M. W. \& Luo, Y. D. (2000), "Managerial ties and firm performance in a transition economy: The nature of a micro-macro link", Academy of Management Journal, Vol. 43 No. 3, pp. 486-501.

Sheng, S., Zhou, K. Z. \& Li, J. J. (2011), "The Effects of Business and Political Ties on Firm Performance: Evidence from China", Journal of Marketing, Vol. 75 No. 1, pp. 1-15.

Smith, W. K. \& Tushman, M. L. (2005), "Managing strategic contradictions: A top management model for managing innovation streams", Organization Science, Vol. 16 No. 5, pp. 522-536.

Srivastava, A., Bartol, K. M. \& Locke, E. A. (2006), "Empowering leadership in management teams: Effects on knowledge sharing, efficacy, and performance", Academy of Management Journal, Vol. 49 No. 6, pp. 12391251.

Su, Z. \& Yang, H. (2018), "Managerial Ties and Exploratory Innovation: An Opportunity-Motivation-Ability Perspective", IEEE Transactions on Engineering Management, Vol. 65 No. 2, pp. 227-238.

Su, Z., Xie, E. \& Wang, D. (2015), "Entrepreneurial Orientation, Managerial Networking, and New Venture Performance in China", Journal of Small Business Management, Vol. 53 No. 1, pp. 228-248.

Wu, M., Huang, X., Li, C. \& Liu, W. (2012), "Perceived Interactional Justice and Trust-in-supervisor as Mediators for Paternalistic Leadership", Management and Organization Review, No. No.1, pp. 97-121.

Xin, K. K. \& Pearce, J. L. (1996), "Guanxi: Connections As Substitutes for Formal Institutional Support", Academy of Management Journal, No. No.6, pp. 1641-1658.

Yang, H., Zheng, Y. \& Zhao, X. (2014), "Exploration or exploitation? Small firms' alliance strategies with large firms", Strategic Management Journal, Vol. 35 No. 1, pp. 146-157.

Zhang, X. \& Bartol, K. M. (2010), "Linking Empowering Leadership and Employee Creativity: The Influence of Psychological Empowerment, Intrinsic Motivation, and Creative Process Engagement", Academy of Management Journal, Vol. 53 No. 1, pp. 107-128. 